\title{
Revised definition of predicted left ventricular mass using ambulatory blood pressure in healthy Korean adults
}

\author{
Bae Keun Kim, Enshi Xu², Bo Youl Choi ${ }^{3}$, Yonggu Lee ${ }^{1}$, Soon Gil Kim², Yukio Yamori ${ }^{4}$ and Jinho Shin²*
}

\begin{abstract}
Background: Left ventricular hypertrophy is influenced by both hemodynamic and non-hemodynamic factors. Ambulatory blood pressure is correlated with left ventricular hypertrophy. We established the influences of hemodynamic and non-hemodynamic factors, including ambulatory blood pressure, on variation in left ventricular mass in healthy Korean adults.

Method: We included 172 subjects (male $=71$, female $=101$ ), with normal body mass index and blood pressure, in an analysis of data from the Yangpyung and Yeoju cohort studies and a tertiary cardiovascular center. Left

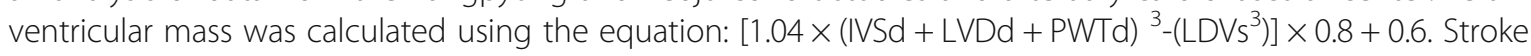
volume was calculated (mL/beat) using Teichholz's formula. Stroke work (SW in gram-meters/beat [g-m/beat]) was computed as ambulatory systolic BP $\times$ stroke volume $\times 0.0144$.

Results: Stroke work was the most important determinant associated with left ventricular mass (adjusted $R^{2}=0.442$, $p<0.001$ ), independent of height ${ }^{2.7}$ and sex. In a regression model including stroke work, height, ${ }^{2.7}$ and sex, the left ventricular mass was predicted by the equation: $43.11+0.61 \times \mathrm{SW}(\mathrm{g}-\mathrm{m} /$ beat $)+9.21 \times$ height $^{2.7}-13.99 \times$ sex $($ male $=1$, female $=2)\left(\right.$ constant $=43.11 \pm 25.88$, adjusted $\left.R^{2}=0.532, p<0.001\right)$.

Conclusion: We examined ambulatory blood pressure, as in previous studies, and identified stroke work, height ${ }^{2.7}$, and sex as important determinants of left ventricular mass in Korean adults of normal weight and normal blood pressure. Ambulatory blood pressure is superior to clinical blood pressure for determining stroke work and predicted left ventricular mass.
\end{abstract}

Keywords: Left ventricular hypertrophy, Ambulatory blood pressure monitoring, Stroke work

\section{Background}

Left ventricular hypertrophy (LVH) is a strong independent risk factor of cardiovascular (CV) mortality in hypertensive patients [1]. Left ventricular (LV) mass is influenced by hemodynamic factors, such as high blood pressure (BP) and stroke work, as well as non-hemodynamic factors [2]. However, a number of patients exhibit levels of LV mass that exceed those needed to sustain hemodynamic load, a condition that has been termed as inappropriately high left ventricular mass (iLVM) [3].

\footnotetext{
* Correspondence: jhs2003@hanyang.ac.kr

2Department of Internal Medicine, Hanyang University College of Medicine, 222 Wangsimni-ro, 04763 Seongdong-gu, Seoul, South Korea

Full list of author information is available at the end of the article
}

iLVM is related to worse CV mortality than appropriate LV mass (aLVM) regardless of the presence of LVH [2]. iLVM may be explained by several mechanisms, including the presence of a higher central BP load, which cannot be explained by brachial BP derived resting stroke work [3], imbalance between growth-promoting factors and growth inhibitory factors [4-6], and BP variability [7]. Genetic factors may also be responsible for exaggerated or overcompensating hypertrophy in response to pressure load [8]. However, the pathogenic mechanism of iLVM is not fully understood [9]. The presence of hidden higher BP load outside of the clinic setting or during sleep that cannot be explained by clinical BP deserves attention.

Considering these probable mechanisms, ambulatory $\mathrm{BP}$ is a possible method for further explaining iLVM. No 
previous studies have examined the utility of ambulatory BP for predicting LV mass. Therefore, we performed this study to establish the influences of hemodynamic and non-hemodynamic factors, including ambulatory BP, on LV mass in healthy Korean adults and to improve our understanding of the mechanisms of iLVM.

\section{Methods}

\section{Study sample and design}

We included $172($ male $=71$, female $=101)$ clinically normal adults of blood pressure below 140/90 $\mathrm{mmHg}$ and normal body mass index (BMI) between 18.5 and $24.9 \mathrm{~kg} / \mathrm{m}^{2}$ in this study. Of these, 54 were drawn from the ongoing Yangpyung and Yeoju Epidemiologic Cohort Survey between January 1, 2014 and June 30, 2015, and 118 were normotensive subjects visiting the Cardiology Center at Hanyang University Hospital, Seoul, Korea from January 1, 2014 to June 30, 2015. The Yangpyeong and Yeoju Epidemiologic Cohort Survey is a longitudinal, community-based cohort study that was launched in 2007 to examine the etiology of CV diseases, supported by the Korea Centers for Disease Control and Prevention.

Height, weight, clinical BP, and heart rate were measured during the study period before ABPM and echocardiography were performed. The study protocol was approved by the Institutional Review Board (IRB) of Hanyang University Medical Center, Seoul.

\section{Blood pressure determination}

Clinical BP was measured as the average of at least 3 measurements by a physician or qualified nurse using a mercury sphygmomanometer. Ambulatory BP was recorded using a TM-2421 blood pressure monitor (A\&D, Saitama, Japan), a device that has undergone independent validation $[10,11]$. The device was applied to the non-dominant arm for $24 \mathrm{~h}$. BP was measured every 15 min during the day and every $30 \mathrm{~min}$ at night (10 PM to $6 \mathrm{AM})$. The subjects were instructed to perform their ordinary activities during monitoring and to stay calm when sensing cuff inflation. Daytime and nighttime were recorded individually according to each subject's self-reported data.

\section{Echocardiography}

Echocardiography was performed on each subject by a single sonographer (JS) using a commercially available machine (iE33; Philips Medical Systems, Andover, MA, USA) with a $1-5 \mathrm{MHz}$ transducer. Mensurements of LV dimensions were performed at or just below the mitral valve tips by the leading edge-to-leading edge method, according to American Society of Echocardiography recommendations with two-dimensional and guided M-mode echocardiogram [12]. LV mass was calculated by the following equation: $[1.04 \times($ IVSd + LVDd + PWTd $) \quad 3-$ LVDd3 $] \times 0.8+0.6$ [13]. LV end-systolic, end-diastolic, and stroke volume (SV) were calculated by Teichholz's method. Stroke work
Table 1 Demographic and hemodynamic parameters in normal individuals

\begin{tabular}{|c|c|c|c|}
\hline & Male $(n=71)$ & Female $(n=101)$ & $p$ \\
\hline Age (years) & $46.8 \pm 16.2$ & $48.1 \pm 11.2$ & 0.565 \\
\hline Height (cm) & $171.0 \pm 6.1$ & $157.3 \pm 5.8$ & $<0.001$ \\
\hline Weight (cm) & $65.9 \pm 6.1$ & $54.3 \pm 5.1$ & $<0.001$ \\
\hline BMI & $22.5 \pm 1.6$ & $22.0 \pm 1.7$ & 0.031 \\
\hline Clinical SBP (mmHg) & $125.9 \pm 15.5$ & $122.3 \pm 19.1$ & 0.188 \\
\hline Clinical DBP (mmHg) & $78.0 \pm 9.7$ & $73.6 \pm 12.6$ & 0.011 \\
\hline $\mathrm{HR}(\mathrm{bpm})$ & $68.9 \pm 12.8$ & $69.1 \pm 9.9$ & 0.913 \\
\hline \multicolumn{4}{|l|}{ Ambulatory BP } \\
\hline 24 h SBP (mmHg) & $120.7 \pm 6.9$ & $115.8 \pm 9.3$ & $<0.001$ \\
\hline 24 h DBP $(\mathrm{mmHg})$ & $74.1 \pm 5.2$ & $72.6 \pm 5.8$ & 0.092 \\
\hline Daytime SBP (mmHg) & $122.1 \pm 15.7$ & $117.2 \pm 14.2$ & 0.033 \\
\hline Daytime DBP (mmHg) & $75.1 \pm 10.5$ & $73.9 \pm 8.9$ & 0.460 \\
\hline Nighttime SBP (mmHg) & $112.4 \pm 13.2$ & $108.3 \pm 14.7$ & 0.063 \\
\hline Nighttime DBP (mmHg) & $68.4 \pm 7.4$ & $67.0 \pm 9.6$ & 0.287 \\
\hline \multicolumn{4}{|l|}{ Echocardiography } \\
\hline IVSTd (cm) & $0.9 \pm 0.1$ & $0.8 \pm 0.1$ & $<0.001$ \\
\hline LVDd (cm) & $5.0 \pm 0.4$ & $4.6 \pm 0.4$ & $<0.001$ \\
\hline PWTd (cm) & $0.8 \pm 0.1$ & $0.7 \pm 0.1$ & $<0.001$ \\
\hline LVDs (cm) & $3.3 \pm 0.3$ & $3.0 \pm 0.3$ & $<0.001$ \\
\hline Stroke volume $(\mathrm{mL})$ & $75.5 \pm 13.0$ & $63.3 \pm 11.4$ & $<0.001$ \\
\hline Clinical SW (g-m/beat) & $137.0 \pm 32.1$ & $111.1 \pm 27.0$ & $<0.001$ \\
\hline Ambulatory SW (g-m/beat) & $131.4 \pm 24.6$ & $105.8 \pm 22.3$ & $<0.001$ \\
\hline LV mass (gram) & $148.4 \pm 29.4$ & $111.0 \pm 24.2$ & $<0.001$ \\
\hline LV mass index $\left(\mathrm{g} / \mathrm{m}^{2.7}\right)$ & $34.9 \pm 7.0$ & $32.9 \pm 8.0$ & 0.087 \\
\hline
\end{tabular}

$B M I$ Body mass index, SBP systolic blood pressure, DBP diastolic blood pressure, IVSTd end-diastolic interventricular septal thickness, $L V$ left ventricular, LVDd end-diastolic left ventricular dimension, LVDs end-systolic left ventricular dimension, PWTd end-diastolic posterior wall thickness, SW Stroke work, LV left ventricular

(SW) is estimated as systolic BP times stroke volume and is converted in gram-meters $(\mathrm{g}-\mathrm{m})$ by multiplying by 0.0144 $(\mathrm{SW}=$ systolic $\mathrm{BP} \times \mathrm{SV} \times 0.0144)$ [14].

\section{Statistical analysis}

Primary variables were adjusted due to demographic differences between subjects selected from cohort surveys and from hospital patients according to the following procedures. Each subject was called as a dummy variable by assigning the state of 1 to hospital subjects and 2 to cohort subjects. Primary echocardiographic measurements (end-diastolic and end-systolic LV internal dimensions and wall thickness), BP, and heart rate were related to dummy variables independent of age and sex $[14,15]$. The variables considered in this qualifying test were therefore adjusted by linear regression analysis (b). Thus, for the adjusted variables (adjV) was adj $\mathrm{V}=\mathrm{V}-\mathrm{b}(\mathrm{x}-\mu)$, where $\mathrm{V}$ was the observed value of the dependent 


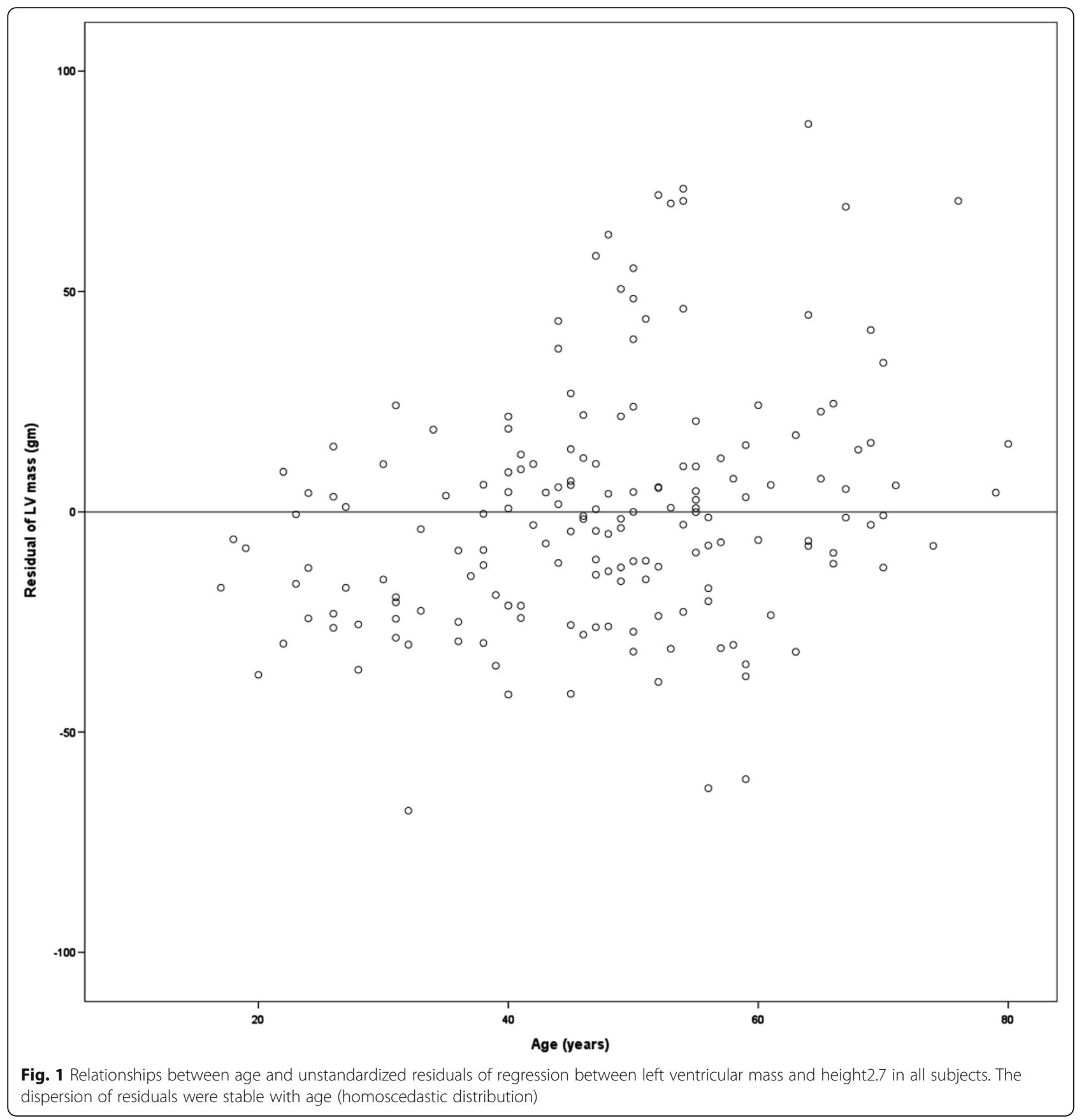

variable, $\mathrm{x}$ was the dummy variable representing the group, and $\mu$ was the average value of the variable representing the group [16].

Data were expressed as frequencies and percentages for qualitative variables and as the mean \pm standard deviation (SD) for quantitative variables. Differences in continuous variables between male and female subjects were assessed with unpaired two-sample $t$-test. Stepwise multiple regression analysis was used to study the hemodynamic and non-hemodynatic predictors of LV mass, with $\mathrm{F}$ to enter and $\mathrm{F}$ to remove set to $P<0.05$ and to $P<0.10$, respectively. Sex was treated as a dummy variable, by assigning 1 to male subjects and 2 to female subjects. Values of 2-tailed $p<0.05$ were considered statistically significant. Data were analyzed using the Statistical Package for Social Sciences (SPSS) 19.0 software (SPSS Inc., Chicago, IL, USA).

\section{Results}

General characteristics of the subjects

General characteristics of male versus female subjects are listed in Table 1. Among the 172 subjects, 71 (41.9\%) were 
male and 101 (58.1\%) were female. In a comparison of general characteristics between male and female subjects, primary echocardiographic measurements, SV, SW, and LV mass were higher in male subjects. However, LV mass index was not different between male and female subjects.

\section{Effects of age on the relationship between LV mass and body size}

LV mass was related to all measures of body size, and was related linearly to height 2.7 . Similar to the results of a previous study [16,17], residuals of the relationship between LV mass and height2.7 were stable in all subjects (Fig. 1).

\section{Equation for LV mass predicted by multiple regression analysis of stroke work calculated using ambulatory blood pressure}

In a stepwise multiple regression analysis, the variance of LV mass associated with independent variables increased from the $44.2 \%$ observed for the univariate relation with ambulatory SW to $53.2 \%$ in a multiple regression model including ambulatory SW in all subjects (slope $=0.61, \beta=$ $0.50, \quad p<0.001 ; \quad$ constant $=43.41, \quad p=0.096)$, height 2.7 (slope $=9.21, \beta=0.16, p=0.049)$ and sex (slope $=-21.51$, $\beta=-0.33, p<0.001$ ) (Tables 2 and 3 ).

\section{Equation for LV mass predicted by multiple regression analysis of stroke work calculated using clinical blood pressure}

In a stepwise multiple regression analysis, the variance of LV mass associated with independent variables increased from the $37.2 \%$ observed for the univariate relation with clinical SW to $50.7 \%$ in a multiple regression model including clinical SW in all subjects (slope $=0.45, \beta=0.44, p$ $<0.001$; constant $=61.79, \quad p=0.019)$, height $2.7 \quad$ (slope $=$ 9.89, $\beta=0.17, p=0.039$ ) and sex (slope $=-17.25, \beta=-0.27$, $\mathrm{p}=0.002$ ) (Tables 2 and 4 ).

\section{Discussion}

We conducted the present study to further our understanding of predicted LV mass. The main finding of our study is that ambulatory BP is better than clinical BP for

Table 2 Stepwise multiple regression model regarding the factor associated with left ventricular mass

\begin{tabular}{|c|c|c|c|}
\hline Model & $R$ & $R^{2}$ & Adjusted $R^{2}$ \\
\hline aSW & 0.668 & 0.446 & 0.442 \\
\hline aSW, Sex & 0.728 & 0.530 & 0.524 \\
\hline aSW, Sex, Height ${ }^{2.7}$ & 0.735 & 0.540 & 0.532 \\
\hline CSW & 0.613 & 0.376 & 0.372 \\
\hline cSW, Sex & 0.709 & 0.503 & 0.497 \\
\hline cSW, Sex, Height ${ }^{2.7}$ & 0.718 & 0.516 & 0.507 \\
\hline
\end{tabular}

aSW stroke work calculated using ambulatory BP, $C S W$ stroke work calculated using clinical BP
Table 3 Multiple regression model for left ventricular mass

\begin{tabular}{lrll}
\hline Factor & Slope & beta & $p$ \\
\hline Constant & 43.41 & & 0.095 \\
aSW & 0.61 & 0.51 & $<0.001$ \\
Sex & -13.99 & -0.33 & $<0.011$ \\
Height $^{2.7}$ & 9.21 & 0.16 & 0.049 \\
\hline
\end{tabular}

aSW stroke work calculated using ambulatory BP

predicting LV mass (Table 2). Hemodynamic factors such as stroke work are the most important factors for predicting LV mass.

LV mass is considered a chronic geometric adaptation to cardiac workload that varies over time. Estimating chronic LV load in a single measurement of cardiac workload at rest in time is too difficult. No previous studies have ever used ambulatory BP for predicting LV mass [16, 17] . A previous study showed that resting systolic BP was at least as closely correlated with LV mass as was waking ambulatory systolic BP in normal subjects. The potential imprecision of a single point measurement may be balanced by the size of the study sample [16]. Therefore, ambulatory BP was used instead of clinical BP in this study as a surrogate for mean LV systolic pressure to calculate SW.

Prediction of inappropriate LV mass generally precludes the consideration of sex differences, body size, and the effects of SW because these variables are included in a prediction equation derived from subjects of normal body weight and normal blood pressure [18]. SW is given by systolic BP $\mathrm{x}$ stroke volume and is converted to gram-meters ( $\mathrm{g}-\mathrm{m}$ ) by multiplying by 0.0144 . The increased accuracy of BP measurements by ABPM may strengthen the association between predicted LM mass and BP, mainly by excluding the white-coat and masked (reverse white-coat) effects. For example, if BP is measured in patients with the white-coat effect, the predicted LV mass is often overestimated. In contrast, predictions of LV mass in patients with masked effects tend to be underestimated.

In a regression analysis using clinical BP, the equation for predicting LV mass was as follows: $61.79+0.45 \times \mathrm{SW}$ (g-m/beat) $+9.89 \times$ height2.7-17.25 $\times$ sex $($ male $=1$, female $=2$ ) $\quad($ constant $=61.79 \pm 26.02$, adjusted R2 $=0.507, p<$ 0.001 ). The $50.7 \%$ of variation of LV mass is explained by this equation. On the other hand, in a regression model

Table 4 Multiple regression model for left ventricular mass

\begin{tabular}{lrll}
\hline Factor & Slope & beta & $p$ \\
\hline Constant & 61.79 & & 0.019 \\
CSW & 0.45 & 0.53 & $<0.001$ \\
Sex & -17.25 & -0.39 & 0.002 \\
Height $^{2.7}$ & 9.89 & 0.17 & 0.039 \\
\hline
\end{tabular}

CSW stroke work calculated using clinical BP 
using ambulatory BP, the equation for predicted LV mass was as follows: $43.11+0.61 \times \mathrm{SW}$ (g-m/beat) $+9.21 \times$ height2.7-13.99 $\times \operatorname{sex} \quad($ male $=1$, female $=2) \quad($ constant $=$ $43.11 \pm 25.88$, adjusted $\mathrm{R} 2=0.532, p<0.001$ ). The $53.2 \%$ of variation of LV mass is explained by that equation. In comparison with a previous study using clinical BP, the variation of LV mass is better explained by this equation using ambulatory BP. SW was the most important determinant of LV mass. Therefore, ambulatory BP is better than clinical BP for determining SW and predicting LV mass.

Previous studies suggested that the equation for predicting LV mass should be: $55.37+6.64 \times$ height $(\mathrm{m} 2.7)+$ $0.64 \times \mathrm{SW}(\mathrm{g}-\mathrm{m} /$ beat $)-13.2 \times$ sex $($ male $=1$, female $=2)$ or $54.9+7.62 \times$ height $(\mathrm{m} 2.7)+0.67 \times \mathrm{SW}(\mathrm{g}-\mathrm{m} /$ beat $)-13.2 \times$ sex $($ male $=1$, female $=2)$. In our regression anaylsis including "ambulatory" SW, height (m2.7) and sex, LV mass was predicted by the equation: $43.11+9.21 \times$ height $2.7+$ $0.61 \times \mathrm{SW}(\mathrm{g}-\mathrm{m} /$ beat $)-13.99 \times \operatorname{sex}($ male $=1$, female $=2)$.

Similar to previous studies, SW was the most important variable determining LV mass in the present study. LV mass remained stable with age (Fig. 1). Other findings of our study were superior to those of previous studies. Variation in LV mass that remained unexplained could be due to methodological errors, undetectable biological mechanism, and environmental or genetic effects $[16,19]$. The extent of technical error may have been reduced by using measurements of ambulatory BP to calculate SW in the present study.

There are limitations to our study. The details of the predicted LV mass equation may not be accurate due to the relatively small sample size and demographic characteristics of the patient population that we included, despite our attempts at statistical adjustment.

\section{Conclusions}

In this study, we demonstrated significant impacts of hemodynamic load as estimated by SW on predictions of LV mass. We found that ambulatory BP is superior to clinical $\mathrm{BP}$ for determining the SW and predicting LV mass. Therefore, our new regression equation for predicted LV mass can be a useful tool for evaluating appropriate LV mass in a number of diseases.

\section{Abbreviations \\ aLVM: Appropriate left ventricular mass; BMI: Body mass index; BP: Blood pressure; CV: Cardiovascular; iLVM: Inappropriate left ventricular mass; IRB: Institutional review board mass; LV: Left ventricular; LVH: Left ventricular hypertrophy; SD: Standard deviation; SV: Stroke volume; SW: Stroke work}

\section{Acknowledgements}

This study received research funding from the Korea Society of Hypertension in 2014.

\section{Availability of data and materials}

Materials and data will be made promptly available to readers without undue qualifications.

\section{Authors' contributions}

BKK and YL were involved with study conception and design; acquisition, analysis, and interpretation of data; and writing of the manuscript. EX was involved with acquisition, analysis, and interpretation of data; BYC and SGK were involved with study conception and design. JS and YY was involved with study conception and design; acquisition, analysis, and interpretation of data; and drafting of the manuscript. All authors reviewed and approved the final manuscript.

\section{Competing interests}

The authors declare that they have no competing interests.

\section{Consent for publication}

All authors have seen and approved the manuscript submitted. We warrant that the article is the Authors' original work. We warrant that the article has not received prior publication and is not under consideration for publication elsewhere. On behalf of all Co-Authors, the corresponding Author shall bear full responsibility for the submission.

\section{Ethics approval and consent to participate}

The study protocol was approved by the Institutional Review Board (IRB) of Hanyang University Medical Center, Seoul.

\section{Author details}

'Division of Cardiology, Department of Internal Medicine, Sung Ae General Hospital, Seoul, South Korea. ${ }^{2}$ Department of Internal Medicine, Hanyang University College of Medicine, 222 Wangsimni-ro, 04763 Seongdong-gu, Seoul, South Korea. ${ }^{3}$ Department of Preventive Medicine, Hanyang University College of Medicine, Seoul, South Korea. ${ }^{4}$ Institute for World Health Development, Mukogawa Women's University, Nishinomia, Japan.

Received: 18 July 2016 Accepted: 30 December 2016

Published online: 16 April 2017

\section{References}

1. Koren MJ, Devereux RB, Casale PN, Savage DD, Laragh JH. Relation of left ventricular mass and geometry to morbidity and mortality in uncomplicated essential hypertension. Ann Intern Med. 1991;114:345-52.

2. Celentano A, Palmieri V, Esposito ND, Pietropaolo I, Crivaro M, Mureddu GF, et al. Inappropriate left ventricular mass in normotensive and hypertensive patients. Am J Cardiol. 2001;87:361-3. A10.

3. de Simone G, Verdecchia P, Pede S, Gorini M, Maggioni AP. Prognosis of inappropriate left ventricular mass in hypertension: the MAVI Study. Hypertension. 2002;40:470-6.

4. Ikeda M, Kohno M, Yasunari K, Yokokawa K, Horio T, Ueda M, et al. Natriuretic peptide family as a novel antimigration factor of vascular smooth muscle cells. Arterioscler Thromb Vasc Biol. 1997;17:731-6.

5. Inoue M, Kanda T, Arai M, Suga T, Suzuki T, Kobayashi I, et al. Impaired expression of brain natriuretic peptide gene in diabetic rats with myocardial infarction. Exp Clin Endocrinol Diabetes. 1998;106:484-8.

6. Chen $\mathrm{HH}$, Burnett JC. Natriuretic peptides in the pathophysiology of congestive heart failure. Curr Cardiol Rep. 2000;2:198-205.

7. Mancia G, Zanchetti A, Agabiti-Rosei E, Benemio G, De Cesaris R, Fogari R, et al. Ambulatory blood pressure is superior to clinic blood pressure in predicting treatment-induced regression of left ventricular hypertrophy. SAMPLE Study Group. Study on Ambulatory Monitoring of Blood Pressure and Lisinopril Evaluation. Circulation. 1997;95:1464-70.

8. Ikeda T, Matsuda K, Itoh H, Shirakami G, Miyamoto $Y$, Yoshimasa T, et al. Plasma levels of brain and atrial natriuretic peptides elevate in proportion to left ventricular end-systolic wall stress in patients with aortic stenosis. Am Heart J. 1997;133:307-14.

9. Devereux RB, Roman MJ, de Simone G, O'Grady MJ, Paranicas M, Yeh JL, et al. Relations of left ventricular mass to demographic and hemodynamic variables in American Indians: the Strong Heart Study. Circulation. 1997;96:1416-23.

10. Imai Y, Sasaki S, Minami N, Munakata M, Hashimoto J, Sakuma H, et al. The accuracy and performance of the A\&D TM 2421, a new ambulatory blood pressure monitoring device based on the cuff-oscillometric method and the Korotkoff sound technique. Am J Hypertens. 1992;5:719-26.

11. O'Brien $\mathrm{E}$, Atkins $\mathrm{N}$, Staessen J. State of the market. A review of ambulatory blood pressure monitoring devices. Hypertension. 1995;26:835-42. 
12. Lim YH, Lee JU, Kim KS, Kim SG, Kim JH, Lim HK, et al. Association between inappropriateness of left ventricular mass and left ventricular diastolic dysfunction: a study using the tissue Doppler parameter, e/e'. Korean Circ J. 2009:39:138-44.

13. Devereux RB, Alonso DR, Lutas EM, Gottlieb GJ, Campo E, Sachs I, et al. Echocardiographic assessment of left ventricular hypertrophy: comparison to necropsy findings. Am J Cardiol. 1986;57:450-8.

14. de Simone G, Devereux RB, Daniels SR, Mureddu G, Roman MJ, Kimball TR et al. Stroke volume and cardiac output in normotensive children and adults. Assessment of relations with body size and impact of overweight. Circulation. 1997:95:1837-43.

15. de Simone G, Roman MJ, Daniels SR, Mureddu G, Kimball TR, Greco R, et al. Age-related changes in total arterial capacitance from birth to maturity in a normotensive population. Hypertension. 1997;29:1213-7.

16. de Simone G, Devereux RB, Kimball TR, Mureddu GF, Roman MJ, Contaldo F, et al. Interaction between body size and cardiac workload: influence on left ventricular mass during body growth and adulthood. Hypertension. 1998:31:1077-82.

17. Shin J, Kim K, Kim S, Kim J, Lim H, Lee B, et al. Influences of Body Size and Cardiac Workload on the Left Ventricular Mass in Healthy Korean Adults with Normal Body Weight and Blood Pressure. Korean Circ J. 2005;35:335-40.

18. Kim BK, Lim YH, Lee HT, Lee JU, Kim KS, Kim SG, et al. Non-Dipper Pattern is a Determinant of the Inappropriateness of Left Ventricular Mass in Essential Hypertensive Patients. Korean Circ J. 2011:41:191-7.

19. de Simone G, Kitzman DW, Palmieri V, Liu JE, Oberman A, Hopkins PN, et al. Association of inappropriate left ventricular mass with systolic and diastolic dysfunction: the HyperGEN study. Am J Hypertens. 2004;17:828-33.

\section{Submit your next manuscript to BioMed Central and we will help you at every step:}

- We accept pre-submission inquiries

- Our selector tool helps you to find the most relevant journal

- We provide round the clock customer support

- Convenient online submission

- Thorough peer review

- Inclusion in PubMed and all major indexing services

- Maximum visibility for your research

Submit your manuscript at www.biomedcentral.com/submit

) Biomed Central 